\title{
Deformation behaviour of high-strength aluminium alloy during forging process using Finite element method
}

\author{
Japeth Obiko $^{a}$ and Fredrick Mwema ${ }^{b^{*}}$
}

${ }^{a}$ Jomo Kenyatta University of Agriculture \& Technology, Nairobi, Kenya

${ }^{b}$ Dedan Kimathi University of Technology, Nyeri, Kenya

\begin{tabular}{l}
\hline A R T I C L E I N F O \\
\hline Article history: \\
Received 20 January 2020 \\
Accepted 6 June 2020 \\
Available online \\
6 June 2020 \\
\hline Keywords: \\
7075 Aluminium \\
Deform-3D \\
Forging \\
Strain \\
Strain rate \\
Stress Temperature
\end{tabular}

\begin{tabular}{l} 
A B S T R A C T \\
\hline The plastic deformation behaviour of 7075 aluminium alloy during the forging process was studied \\
using Deform 3D software. The simulation process was carried out at a constant die velocity of 5 \\
$\mathrm{~mm} / \mathrm{s}$ and a varying forging temperature between $250^{\circ} \mathrm{C}$ and $400^{\circ} \mathrm{C}$. The results showed that the \\
forging load increased with a decrease in the forging temperature. The effective strain rate, strain \\
and stress distribution were inhomogeneous across the deformed workpiece, indicating \\
nonuniform forging process. It was observed that the reduction in the forging temperature during \\
the process was responsible for the inhomogeneity. The flow curves obtained using finite element \\
simulation code are consistent with experimental results reported in literature.
\end{tabular}

Stress Temperature

\section{Introduction}

The 7075 aluminium alloy has a wide application in the aerospace and automobile industries (Jenab \& Taheri, 2011). These alloys possess good mechanical and physical properties such as high strength and attractive corrosion behaviour to various media (Guo et al. 2015; Jenab \& Karimi Taheri, 2011). These desirable mechanical properties are closely related to the microstructure (Rajamuthamilselvan \& Ramanathan, 2011), which largely depends on the thermomechanical processing of the alloys (TaheriMandarjani et al. 2015). Most structural components are produced through the forging process (Rajamuthamilselvan \& Ramanathan, 2011), which involves the high application of forces and stresses leading to a complex deformation process (Dieter, 1988). The material flow behaviour depends on the forging parameters such as temperature, strain rate and strain (Lin et al., 2008). The metal flow behaviour to a large extent affects the final microstructure of the material (Rajamuthamilselvan \& Ramanathan, 2011). The material workability can be improved by understanding the metal flow behaviour.

\footnotetext{
* Corresponding author.

E-mail addresses: fredrick.mwema@dkut.ac.ke (F. Mwema)

(C) 2021 Growing Science Ltd. All rights reserved.

doi: $10.5267 /$ j.esm.2020.6.001
} 
Research has been carried out on the hot workability of 7075 aluminium alloys (Guo et al., 2015; Rokni et al. 2011; Zhang et al. 2011). The focus has been on the development of the constitutive equations can accurately predict the flow stress behaviour. However, inhomogeneous deformation behaviour is experienced due to deformation parameters (Christiansen et al., 2016). Carrying out deformation process through trial and error method based on the expertise of the operators (Maarefdoust, 2012), makes the production process expensive and time-consuming (Oh et al. 1991). As such, there has been an increasing application of computer simulations to predict material behaviour during metal working (e.g. forging) process (Zhang et al. 2009). Although considerable work on FEM simulation of the metal flow behaviour for a variety of metals and alloys has been reported, there is limited information on FEM simulation of 7075 aluminium alloys. In this study, the forging process of 7075 aluminium alloy was simulated using Deform3D software. The effect of forging temperature at a constant die speed on the flow behaviour was highlighted.

\section{Finite element method theory}

The visco-plastic material can be conveniently used for the analysis of metal forming process. Oh (1982) reported that during the forging process, rigid visco-plastic material showed that the flow stress depends on the strain rate, temperature and strain. The constitutive equations for solving the deformation behaviour as affected by the deformation parameters are based on the variational principle. The NewtonRaphson iterative method is widely used to solve these non-linear algebraic equations (Asadi et al., 2011). The deformation governing equations have been widely reported in the literature (Lee et al., 2004; Oh et al., 1991). These equations are summarised as follows:

$$
\sigma_{i j}^{\prime}=\frac{2}{3} \frac{\bar{\sigma}}{\bar{\varepsilon}} \dot{\varepsilon}_{i j}
$$

From Eq. (1), $\sigma_{i j}^{\prime}$ is the deviatoric stress, the effective stress $(\bar{\sigma})$ and strain rate $(\dot{\bar{\varepsilon}})$ are given in the following equations:

$$
\begin{aligned}
& \bar{\sigma}=\sqrt{\frac{3}{2} \sigma^{\prime}{ }_{i j} \sigma^{\prime}{ }_{i j}} \\
& \dot{\bar{\varepsilon}}=\sqrt{\frac{2}{3} \dot{\varepsilon}_{i j} \dot{\varepsilon}_{i j}}
\end{aligned}
$$

To solve the above governing equations in FEM, a weak form of the expression can be developed through the shape functions as represented by the variational principle below:

$$
\int_{v} \bar{\sigma} \delta \dot{\bar{\varepsilon}} d V+K \int_{v} \dot{\varepsilon}_{v} \delta \dot{\varepsilon}_{v} d V-\int_{S f} f_{i} \delta v_{i} d S=0,
$$

where $K$ is a penalty constant which shows volume change, $V$ and $S$ represent the volume and surface of the specimen respectively. Since the forging temperature plays a crucial role during the deformation process, the temperature distribution of the anvil or workpiece can be solved using the energy balance equation (Kukuryk, 2012):

$$
\nabla^{T} .(k \nabla T)+\dot{q}-\rho \dot{c_{p}} \dot{T}=0,
$$

where $T$ is the temperature, $k$ is the thermal conductivity, $\dot{q}$ is the rate of heat generation, $\rho$ is the specific density and $c_{p}$ is the specific heat. During plastic deformation process the heat generated is given as:

$$
\dot{q}=\alpha \bar{\sigma} \dot{\bar{\varepsilon}},
$$


In Eq. (6), $\alpha$ is the efficiency of the heat generated, which is the amount of mechanical energy converted in heat during plastic deformation. Then, the energy balance equation can be written as follows incorporating the shape functions for the weak function estimation of the energy equation:

$$
\int_{v} k T{ }_{, i} \delta T{ }_{i} d V+\int_{v} \rho c_{p} \dot{T} \delta T d V-\int_{v} \alpha \bar{\sigma} \dot{\bar{\varepsilon}} \delta T_{i} d V-\int_{S} q_{n} \delta T d S=0
$$

The heat flux normal to the surface boundary is denoted $q_{n}$ which account to the amount of heat lost into the environment by radiation and convection and the friction heat gained due to friction shear stresses between the workpiece and the anvil. Eq. (7) can be used to calculate the temperature distribution in the workpiece and the anvil. According to (Kukuryk, 2012) and (Oh, 1982), the friction between the workpiece and the anvil occur due to the presence on the frictional shear stress $\tau$ expressed as:

$$
\tau=-m k\left[\frac{2}{\pi} \arctan \left(\frac{\Delta V_{s}}{u_{0}}\right)\right] t
$$

In Eq. (8), $m$ represents the friction factor, $k$ is the shear yield stress, $\Delta V S$ is relative slipping velocity vector of the workpiece and $t$ is a vector (unity) and $u_{0}$ is a small positive number in relative to $\Delta V s$.

\section{Finite element modelling (FEM)}

The general procedure for undertaking FEM is represented by Fig. 1. The procedure was implemented in Deform ${ }^{\circledR}$ 3D software to study the forging process of 7075 aluminium alloy. The definition of the mathematical model is based on the Eqs. 1 to 8, the speed and temperature of the die were set as the natural and essential boundary conditions respectively.

\section{Validation:}
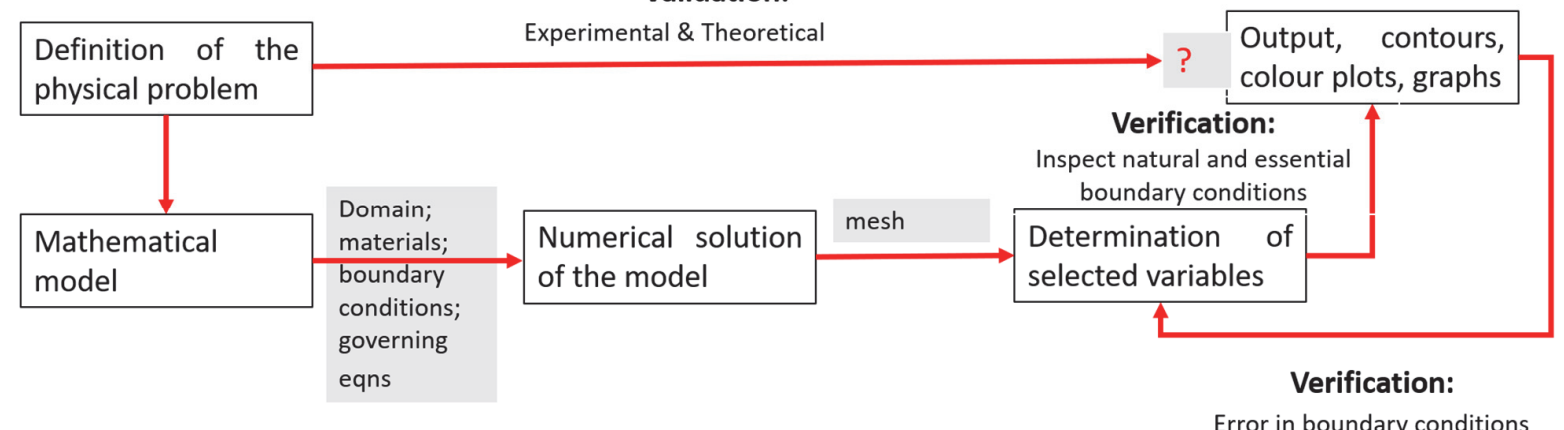

Fig. 1. General finite element method procedure

The model in this study was based on the existing material properties which are in-built in the software database. Cylindrical specimen measuring $10 \mathrm{~mm}$ diameter and $15 \mathrm{~mm}$ length like that used for physical laboratory forging simulation was defined. The workpiece was taken to be a rigid viscoplastic material while the dies were rigid. The coefficient of friction was assumed constant $(\mu=0.3$, which represents friction for hot forging with lubrication). The forging environment was maintained at a constant ambient temperature of $20^{\circ} \mathrm{C}$ and the die temperature was set at $50^{\circ} \mathrm{C}$. The forging temperature was varied between $250^{\circ} \mathrm{C}$ to $400^{\circ} \mathrm{C}$ at an interval of $50^{\circ} \mathrm{C}$. The upper die was set to move at a constant velocity of $5 \mathrm{~mm} / \mathrm{s}$ while the lower die remained stationary. The loaded simulation assembly and deformed samples are as shown in Fig. 2 (a) and 2(b), respectively. 


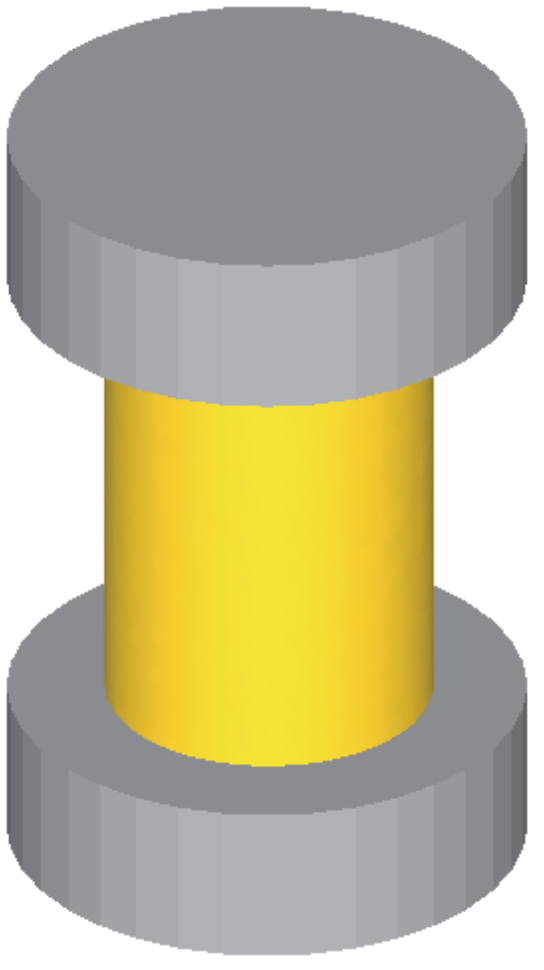

(a)

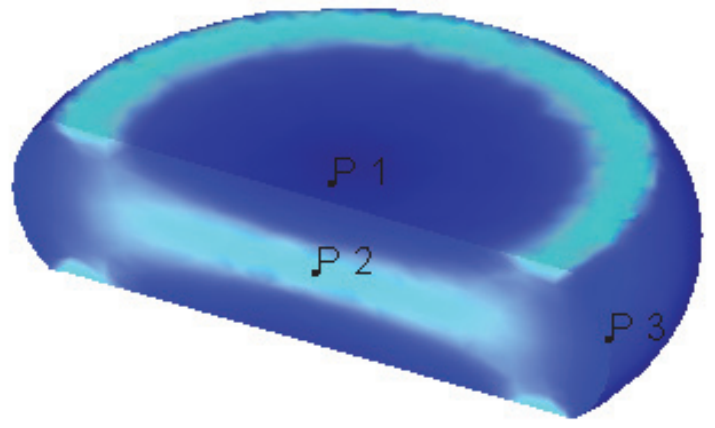

(b)

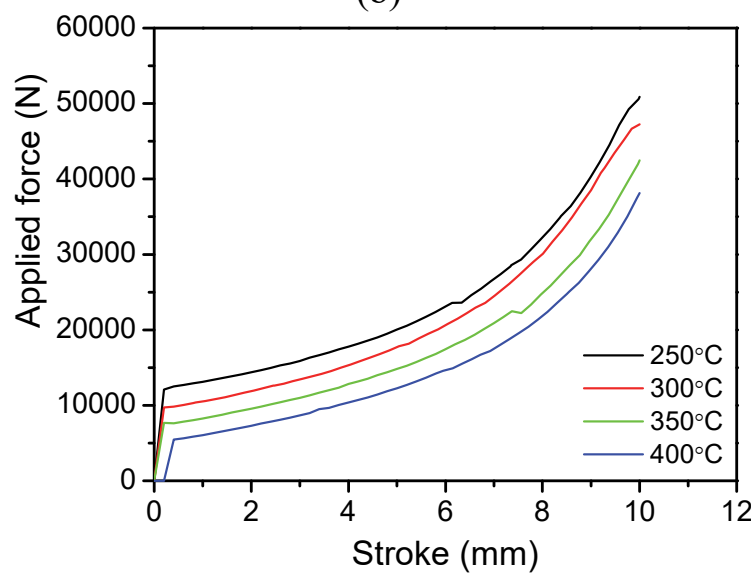

(c)

Fig. 2. (a) Loaded finite element model (b) deformed specimen (c) load-stroke curves under different forging temperatures.

\section{Results and discussion}

\subsection{Load-stroke flow curves}

The load-stroke flow curves for the forging simulation process under different forging temperature $\left(250^{\circ} \mathrm{C}, 300^{\circ} \mathrm{C}, 350^{\circ} \mathrm{C}\right.$ and $\left.400^{\circ} \mathrm{C}\right)$ at a constant die velocity of $5 \mathrm{~mm} / \mathrm{sec}$ are shown in Fig. 2(c). The flow curves show that the forging load increases as the temperature decreases. Similarly, it has been reported earlier that the forging load increases with an increase the strain rate (strain rate $\dot{\varepsilon}=V_{d} / h_{0}$ where $V_{d}$ is the die velocity and $h_{0}$ is the initial height of the workpiece) (Obiko et al. 2019). The forging loads decreased with an increase in the forging temperature, which can be attributed to the occurrence of the softening mechanism that enhances dislocation movement at higher forging temperatures. At lower forging temperatures, the generation rate of dislocation density is high leading to work hardening. Hence, higher forging loads are required during the forging process. At the initial stages of forging, a rapid increase in the forging loads was observed with an increase in stroke displacement. This increase in forging load is due to the resistance of the material to the deformation process resulting from dislocation density generation and precipitation hardening (Guo et al., 2015). As deformation continues, the forging load attain a relatively slow increase rate due to dynamic softening. This variation in the flow curve behaviour during the deformation process has been reported in the literature (Guo et al., 2015; Rajamuthamilselvan \& Ramanathan, 2011; Rokni et al., 2011). It was also observed that at higher stroke displacement $(\sim>6 \mathrm{~mm})$ there was an abrupt increase in the forging load. This phenomenon may be due to the increase in the coefficient of friction between the workpiece and the die. Research has shown that the coefficient of friction is not constant ( $\mathrm{Li}$ et al. 2009). The increase in friction coefficient occurs due to either the lateral side of the workpiece making contact with the die at higher strain levels or decreases in the thickness of the lubricating film as reported by (Li et al., 2009). Therefore, the effect of friction on 
metal flow behaviour must be corrected before further analysis. Analytical equations for correcting the effect of friction during the forging process have been developed by Evans and Scharning (2001).

From Fig. 2 (c), it was observed that the maximum forging loads were $51 \mathrm{kN}\left(250^{\circ} \mathrm{C}\right), 47 \mathrm{kN}\left(300^{\circ} \mathrm{C}\right)$, $43 \mathrm{kN}\left(350^{\circ} \mathrm{C}\right)$ and $38 \mathrm{kN}\left(400^{\circ} \mathrm{C}\right)$. The results showed a decreasing trend as the forging temperature increases. This characteristic behaviour shows the dependence of forging load on the processing parameters such as temperature, strain and strain rate (Obiko et al., 2019). Therefore, the load-stroke flow curves can be used for estimating the forging load required for any given forging conditions and material. Hence, provides the means to estimate the capacity of the forging machine required for real industrial applications.

\subsection{Forging temperature distribution}

During the forging simulation process, the loss of temperature with time for all the simulation conditions is shown in Fig. 3. Three points (P1, P2 and P3) were selected from the deformed sample as shown in Fig. 2(b) to monitor the forging process. It can be seen that there was a sharp temperature drop at the top surface (P1) compared to P2 and P3. The loss in temperature can be attributed to the chilling effect due to heat transfer from the workpiece to the die. The chilling effect during the forging process has been reported to be due to the extract of heat from the workpiece leading to inhomogeneous deformation process (Rasti et al. 2011). Point P2 and P3 have relatively similar temperature changes during the forging process. The reason may be that the two points are not in contact with any surface but exchange heat with the environment. The two points (P2 and P3) undergoes severe plastic deformation than P1. In these points, more heat may be generated and then compensate the heat loss at the dieworkpiece interface to regulate the forging temperature. The temperature drop pattern was similar in all the forging conditions as shown in Fig. 3. It was observed that the temperature loss increased with an increase in the forging temperature. At the forging temperature of $250^{\circ} \mathrm{C}$, point $\mathrm{P} 1$ had a temperature drop of $75^{\circ} \mathrm{C}$ compared to $163^{\circ} \mathrm{C}$ for higher forging temperature of $400^{\circ} \mathrm{C}$. A similar trend of higher temperature loss with increase in forging temperature was observed in the other two points. This phenomenon needs more investigation to establish the cause of this behaviour.

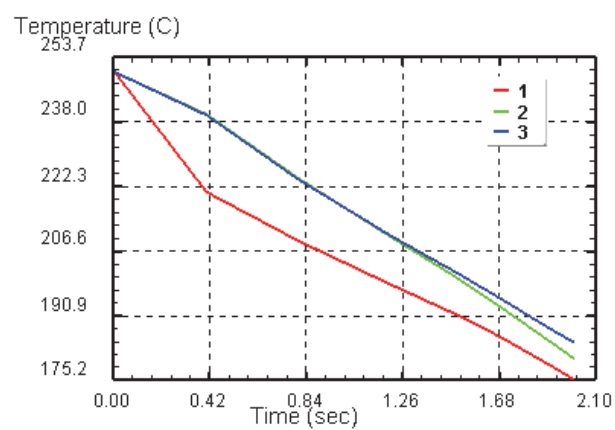

(a) $250^{\circ} \mathrm{C}$

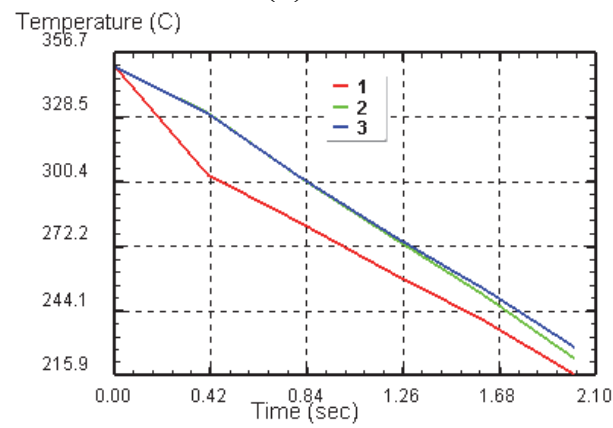

(c) $350^{\circ} \mathrm{C}$

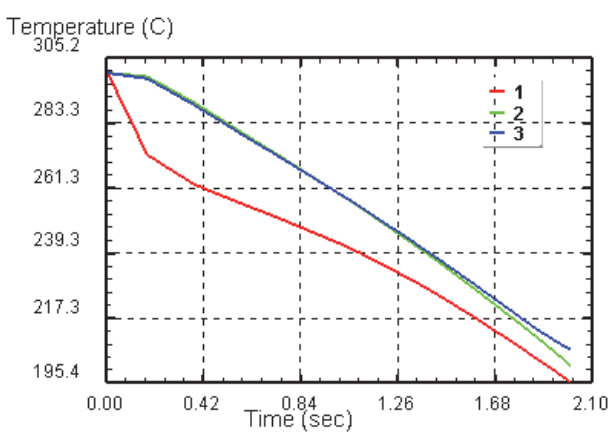

(b) $300^{\circ} \mathrm{C}$

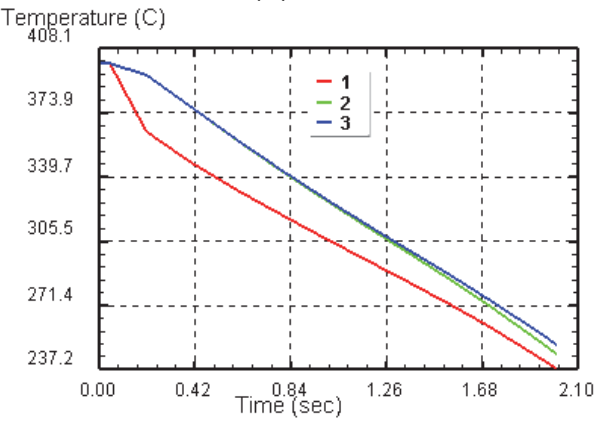

(d) $400^{\circ} \mathrm{C}$

Fig. 3. Temperature distribution at three points in the deformed sample 


\subsection{Effective strain distribution during forging process}

Fig. 4 shows the strain distribution with time across the deformed workpiece for the selected three points during the simulation process. As shown, it was observed that the effective strain varied at different points of the deformed workpiece. This shows that the deformation process was inhomogeneous for all the forging conditions. The selected points represent the three zones that develop during the hot deformation process as categorised by Rasti et al. (2011). Point P1 represents the dead zone which experiences the lowest effective strain as compared to points $\mathrm{P} 2$ and $\mathrm{P} 3$. This is so because the frictional stresses between the workpiece and the die act towards the centre of the workpiece, hence restricting the lateral metal flow. Point P2 represents the region that undergoes intensive shearing and had the highest effective strain during the forging process. In this region, severe plastic deformation occurs leading to grain refinement due to enhanced dynamic softening mechanisms (Obiko et al., 2019). On the other hand, point P3 which is at the outer surface, experiences moderate deformation since there is no restriction to metal flow during deformation. As such, P3 had lower strain than point P2 but higher than point P1. In point $\mathrm{P} 3$, the microstructure evolution during deformation is less expected (Rasti et al., 2011).

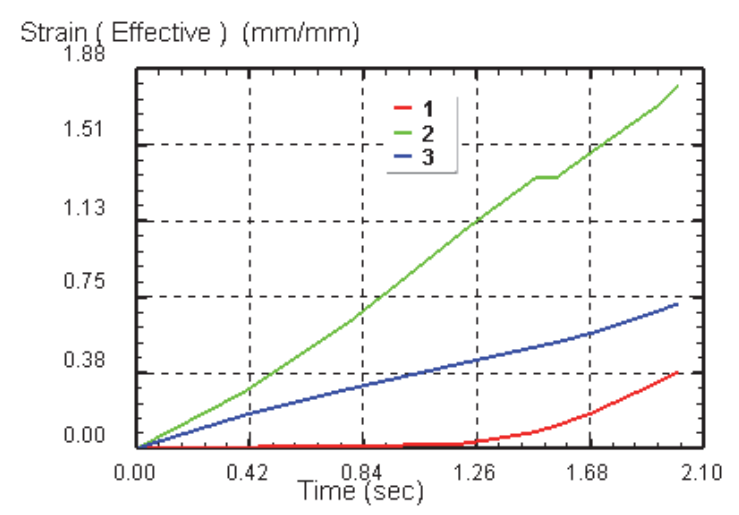

(a) $250^{\circ} \mathrm{C}$

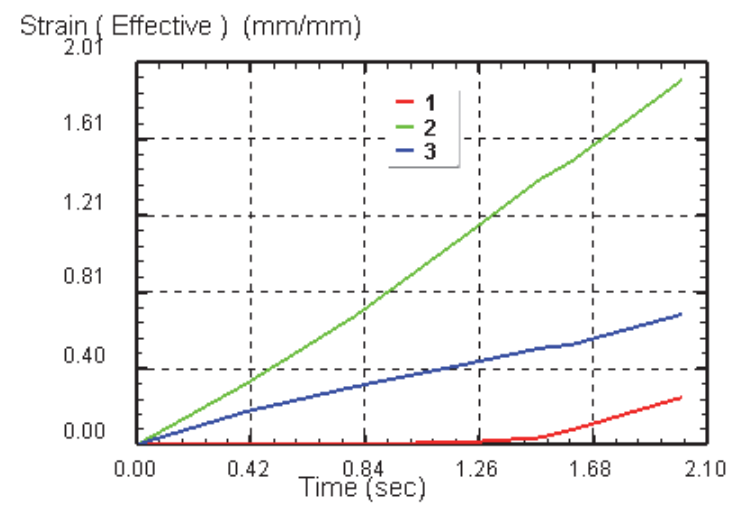

(c) $350^{\circ} \mathrm{C}$

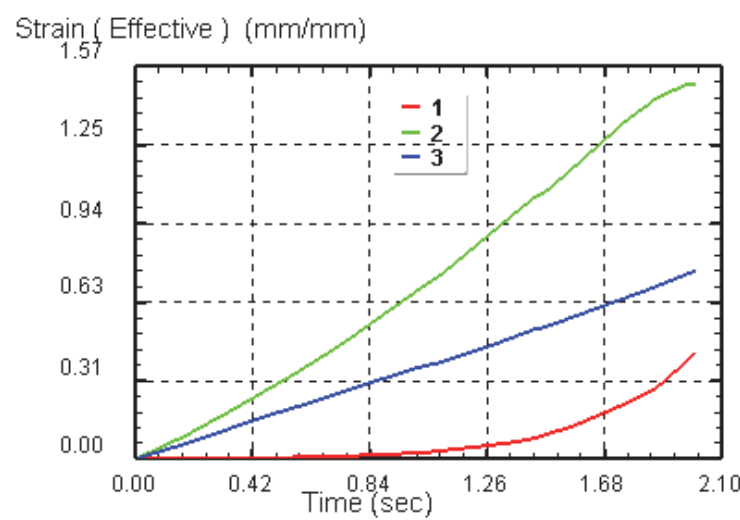

(b) $300^{\circ} \mathrm{C}$

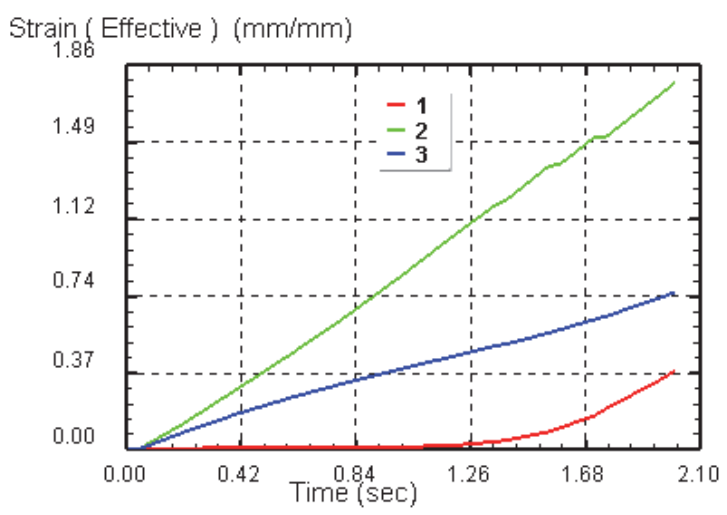

(d) $400^{\circ} \mathrm{C}$

Fig. 4. Variation of the effective strain at three points in the deformed sample.

\subsection{Effective stress distribution during forging process}

The effective stress against forging time curves for all forging temperature at constant die velocity are given in Fig. 5 for regions P1, P2 and P3. It can be seen that at the initial stages of deformation, the effective stress increased rapidly up to approximately 0.42 seconds. This can be attributed to a higher rate of dislocation density generation hindering plastic deformation process. At this stage, work hardening dominates the deformation process (Zhu, 2018). In all the forging temperature, P3 exhibited 
the lowest effective stress as shown since the metal flow was not restricted, hence there was no resistance to plastic deformation. However, point P3 had the maximum tensile stress which may lead to flow instabilities such as wedge cracking. The maximum tensile stress at P3 decreased with an increase in the forging temperature from $183 \mathrm{MPa}\left(250^{\circ} \mathrm{C}\right)$ to $135 \mathrm{MPa}\left(400^{\circ} \mathrm{C}\right)$. The maximum effective stresses were observed at P1 and P2 after the forging process as shown in Fig. 5. The higher effective stresses can be attributed to the restriction of metal flow and the drop in the forging temperature. This leads to the application of higher forging forces during the deformation process. It was observed that the effective stresses increased gradually after 0.42 seconds until the end of the forging process. This flow behaviour was attributed to the drop in the forging temperature as shown in Fig. 3.

\subsection{Effective strain rate distribution}

The effective strain rate distribution for all the forging temperatures are shown in Fig. 6 . The results showed that the effective strain rate at point P2 was higher than the other two points (P1 and P3). This shows that the largest plastic deformation process occurred at P2. Point P1 experienced a constant effective strain rate up to 0.84 seconds of forging time. Thereafter, the effective strain rate increases exponentially as the deformation continues. The change in effective strain rate can be attributed to an increase in frictional stresses between the workpiece and the die. Point P3 had a rapid increase in the effective strain rate at the initial stage of forging below 0.42 seconds. Then, a decrease in the effective strain rate was observed and maintained at a relatively same level especially at lower forging temperature $\left(250^{\circ} \mathrm{C}\right.$ and $\left.300^{\circ} \mathrm{C}\right)$. The variation in the effective strain rate shows that the deformation process was not homogeneous. It is suggested that to achieve a homogeneous deformation process, industrial forging parameters require an optimisation approach.

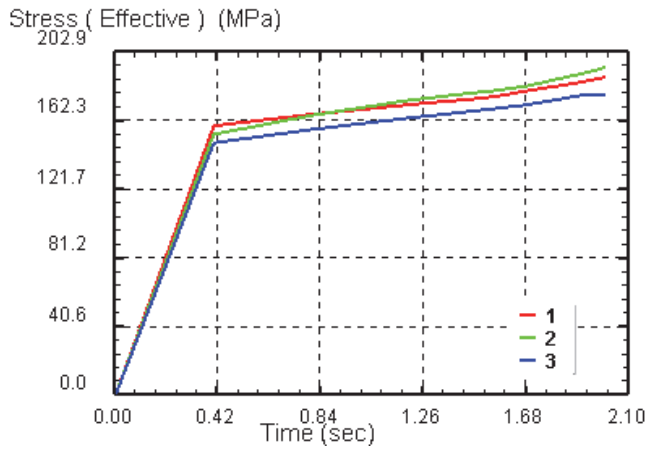

(a) $250^{\circ} \mathrm{C}$

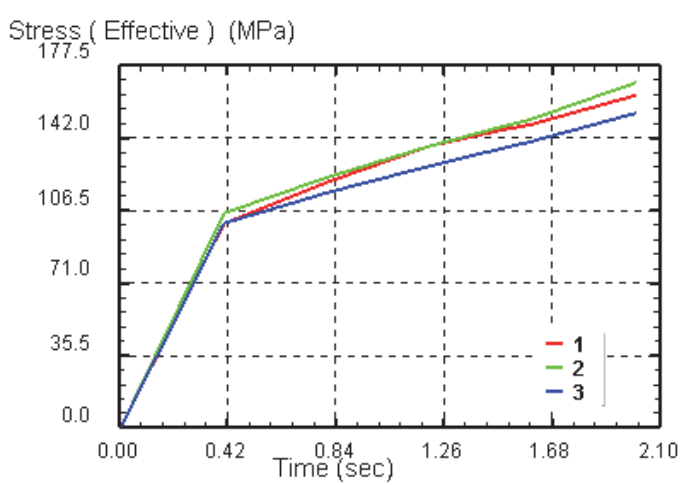

(c) $350^{\circ} \mathrm{C}$

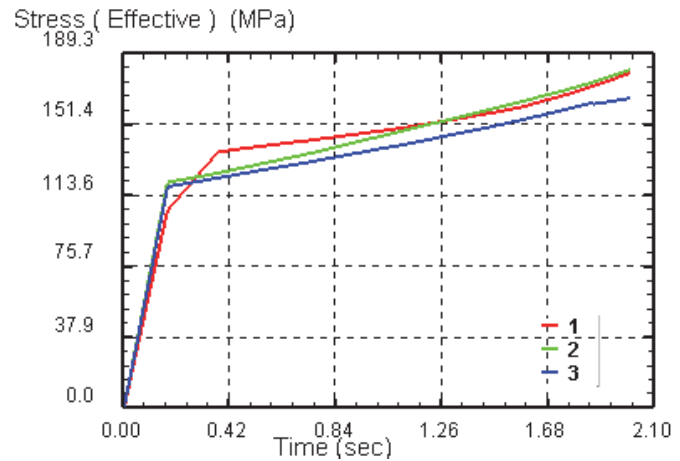

(b) $300^{\circ} \mathrm{C}$

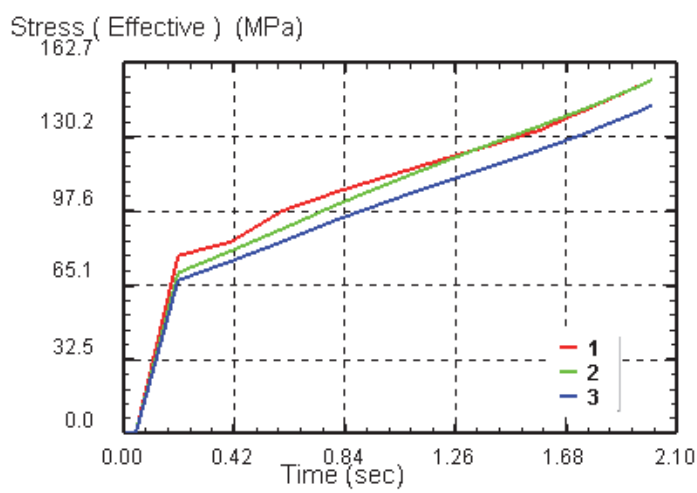

(d) $400^{\circ} \mathrm{C}$

Fig. 5. Variation of the effective stress at three points in the deformed sample. 


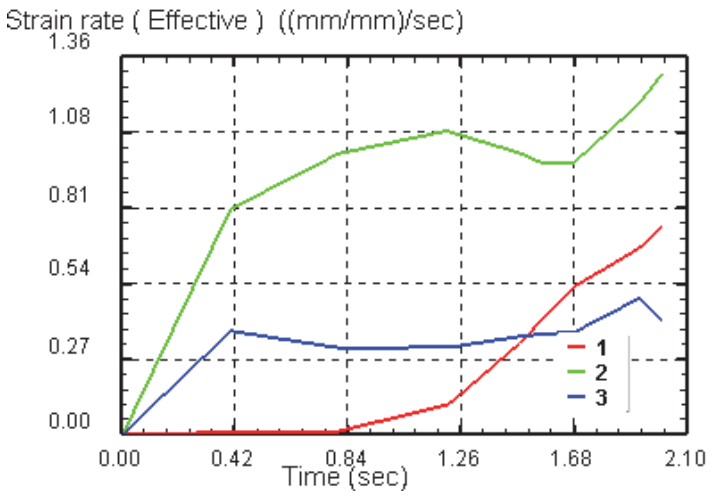

(a) $250^{\circ} \mathrm{C}$

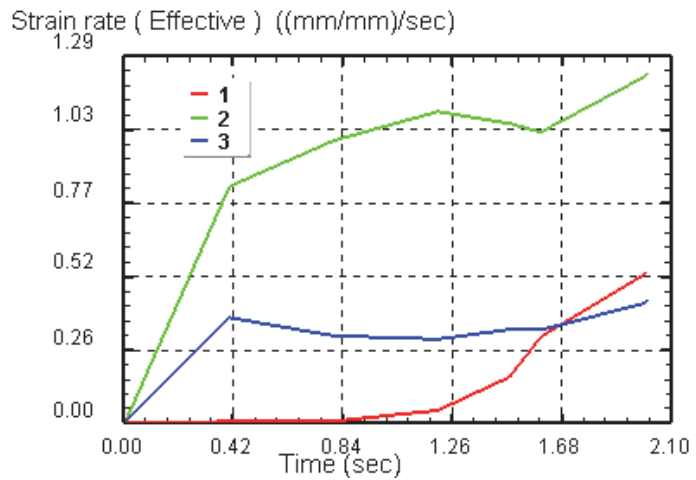

(c) $350^{\circ} \mathrm{C}$

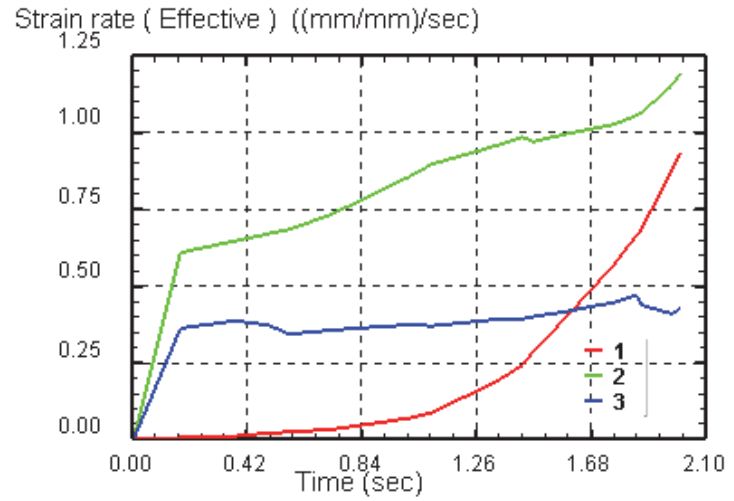

(b) $300^{\circ} \mathrm{C}$

Strain rate (Effective) ((mm/mm)/sec)

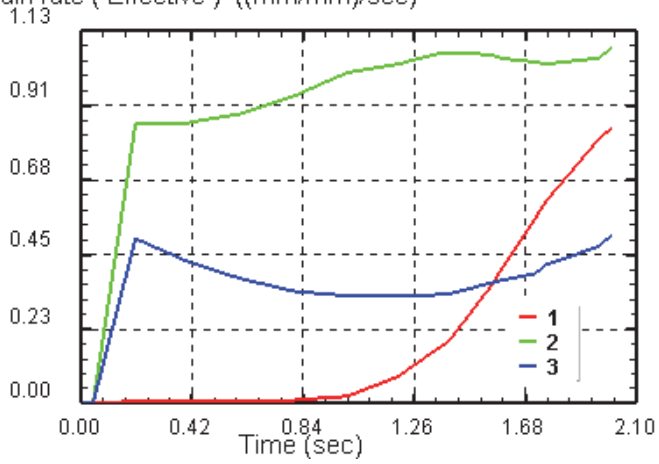

(d) $400^{\circ} \mathrm{C}$

Fig. 6. Variation of the effective strain rate at three points in the deformed sample.

\section{Conclusion}

From the forging simulation of 7075 aluminium alloy at constant die velocity of $5 \mathrm{~mm} / \mathrm{s}$ and a range of different forging temperature $\left(250^{\circ} \mathrm{C}-400^{\circ} \mathrm{C}\right)$ using Deform-3D software, the following conclusions were drawn:

1. The load-stroke flow curves showed that the forging loads increased with a decrease in the forging temperature. A variation in forging temperature was observed across the deformed workpiece during the entire forging process. The change in the forging temperature caused an inhomogeneous deformation process. The forging temperature drop showed a similar flow pattern for all forging temperature conditions.

2. The effective strain and stress distribution across the workpiece exhibited inhomogeneous deformation behaviour. Point P2 which lies at the mid-height of the workpiece experienced the highest strain due to large plastic deformation compared to the other outer surfaces (points P1 and P3). Points P1 and P2 exhibited higher effective stress while point P3 had the maximum tensile stress. The higher effective stress at P1 can be attributed to a rapid drop in forging temperature due to the chilling effect, which may lead to the formation of flow instabilities. The distribution of effective strain rate was inhomogeneous, which further showed that the forging process was inhomogeneous. The variation in effective strain, stress and strain rate was due to the temperature variation during the forging process.

\section{References}

Asadi, P., Mahdavinejad, R. A., \& Tutunchilar, S. (2011). Simulation and experimental investigation of FSP of 
AZ91 magnesium alloy. Materials Science \& Engineering A, 528(21), 6469-6477.

Christiansen, P., Martins, P. A. F., \& Bay, N. (2016). Friction Compensation in the Upsetting of Cylindrical Test Specimens. Experimental Mechanics.

Evans, R. W., \& Scharning, P. J. (2001). Axisymmetric compression test and hot working properties of alloys. Materials Science and Technology, 17(8), 995-1004.

Guo, L., Yang, S., Yang, H., \& Zhang, J. (2015). Processing map of as-cast 7075 aluminum alloy for hot working. Chinese Journal of Aeronautics, 28(6), 1774-1783.

Jenab, A., \& Karimi Taheri, A. (2011). Evaluation of low strain rate constitutive equation of 7075 aluminium alloy at high temperature. Materials Science and Technology, 27(6), 1067-1072.

Kukuryk, M. (2012). Analysis of deformation and damage evolution in hot elongation forging. Archives of Metallurgy and Materials, 57(2), 417-424.

Lee, K. H., Lee, S. R., \& Yang, D. Y. (2004). Rigid-plastic finite element analysis of incremental radial forging process using the automatic expansion of domain scheme. Engineering Computations (Swansea,Wales),21(5),470-487.

Li, Y. P., Onodera, E., Matsumoto, H., \& Chiba, A. (2009). Correcting the stress-strain curve in hot compression process to high strain level. Metallurgical and Materials Transactions A: Physical Metallurgy and Materials Science, 40(4), 982-990.

Lin, Y. C., Chen, M. S., \& Zhong, J. (2008). Numerical simulation for stress/strain distribution and microstructural evolution in 42CrMo steel during hot upsetting process. Computational Materials Science, 43(4), 1117-1122.

Maarefdoust, M. (2012). Simulation of finite volume of hot forging process of industrial gear. International Proceedings of Computer Science and Information Technology, 57(Icni), 111-115.

Dieter, G. (1988). Mechanical Metallurgy. Mcgraw Hill New York

Obiko, J. O., Mwema, F. M., \& Bodunrin, M. O. (2019). Finite element simulation of X20CrMoV121 steel billet forging process using the Deform 3D software. SN Applied Sciences, 1(9), 1044.

Obiko, Japheth O, Mwema, F. M., \& Akinlabi, E. T. (2019). Strain rate-strain/stress relationship during isothermal forging:A Deform-3D FEM. Engineering Solid Mechanics, 8, 1-6.

Oh, S. I. (1982). Finite element analysis of metal forming processes with arbitrarily shaped dies. International Journal of Mechanical Sciences, 24(8), 479-493.

Oh, S. I., Wu, W. T., Tang, J. P., \& Vedhanayagam, A. (1991). Capabilities and applications of FEM code deform: the perspective of the developer. Journal of Materials Processing Tech., 27(1-3), 25-42.

Rajamuthamilselvan, M., \& Ramanathan, S. (2011). Hot deformation behaviour of 7075 alloy. Journal of Alloys and Compounds. https://doi.org/10.1016/j.jallcom.2010.09.139

Rasti, J., Najafizadeh, A., \& Meratian, M. (2011). Correcting the stress-strain curve in hot compression test using finite element analysis and Taguchi method. International Journal of ISSI, 8(1), 26-33.

Rokni, M. R., Zarei-Hanzaki, A., Roostaei, A. A., \& Abedi, H. R. (2011). An investigation into the hot deformation characteristics of 7075 aluminum alloy. Materials and Design, 32(4), 2339-2344.

Taheri-Mandarjani, M., Zarei-Hanzaki, A., \& Abedi, H. R. (2015). Hot ductility behavior of an extruded 7075 aluminum alloy. Materials Science and Engineering A, 637, 107-122.

Zhang, Z. J., Dai, G. Z., Wu, S. N., Dong, L. X., \& Liu, L. L. (2009). Simulation of 42CrMo steel billet upsetting and its defects analyses during forming process based on the software DEFORM-3D. Materials Science and Engineering A, 499(1-2), 49-52.

Zhang, Z., Yang, Y., \& Meng, M. (2011). Hot deformation behavior of 7075 aluminum alloy bar compressed with different orientation at elevated temperature. Advanced Materials Research, 217-218, 1729-1732.

Zhu, L. (2018). A two-stage constitutive model of X12CrMoWVNbN10-1-1 steel during elevated temperature. Materials Research Express. 
(C) 2021 by the authors; licensee Growing Science, Canada. This is an open access article distributed under the terms and conditions of the Creative Commons Attribution (CC-BY) license (http://creativecommons.org/licenses/by/4.0/). 